\title{
Micromechanical Assessment of Al/Y-substituted NASICON Solid Electrolytes
}

\author{
Juliane Franciele Nonemacher $^{1}$, Sahir Naqash ${ }^{1,2}$, Frank Tietz ${ }^{1,2}$, Jürgen Malzbender ${ }^{1 *}$ \\ ${ }^{1}$ Forschungszentrum Jülich GmbH, Institute of Energy and Climate Research, 52425 Jülich, \\ Germany \\ ${ }^{2}$ Forschungszentrum Jülich GmbH, Helmholtz-Institute Münster, 52425 Jülich, Germany
}

\begin{abstract}
Al/Y-substituted NASICON solid electrolytes are promising for novel solid state batteries. The solid solutions $\mathrm{Na}_{1+2 x} \mathrm{Al}_{x} \mathrm{Y}_{x} \mathrm{Zr}_{2-2 x}\left(\mathrm{PO}_{4}\right)_{3} \quad(\mathrm{NAYZP} x)$ and $\mathrm{Na}_{3+2 x} \mathrm{Al}_{x} \mathrm{Y}_{x} \mathrm{Zr}_{2-2 x}\left(\mathrm{SiO}_{4}\right)_{2}\left(\mathrm{PO}_{4}\right)$ (NAYZSiPx) that crystallize in this structure are characterized by depth-sensitive indentation technique to determine their micro-mechanical properties. NAYZPx is rhombohedral, whereas NAYZSiPx changes from monoclinic to rhombohedral phase depending on substitutional level and temperature. For rhombohedral NAYZPx elastic moduli are in the range $~ 72$ to $82 \mathrm{GPa}$ and hardness values are in the range $\sim 4.8$ to $5.8 \mathrm{GPa}$, whereas for NAYZSiP $x$ the elastic moduli are with the range $\sim 72$ to $88 \mathrm{GPa}$ and hardness $\sim 5.6$ to $7.6 \mathrm{GPa}$, respectively. The fracture toughness values for both systems, as determined by Vickers indentation, are rather independent of the applied load being with the range 1.30 to $1.58 \mathrm{MPa} \cdot \mathrm{m}^{0.5}$. Cracks typically show a mixed intergranular/transgranular crack mode.
\end{abstract}

Keywords: Solid electrolyte; NASICON; Mechanical properties; Elastic modulus; Hardness; Fracture Toughness;

\footnotetext{
* Corresponding author: j.malzbender@fz-juelich.de, tel.: ++ 492461 6964, fax: ++ 492461613699
} 


\section{Introduction}

Structural stability and ionic conductivity makes NASICON ( $\mathrm{Na}^{+}$Super Ionic Conductor) materials promising for the application as solid electrolytes for solid-state sodium batteries. Originally the system $\mathrm{Na}_{1+x} \mathrm{Zr}_{2} \mathrm{P}_{3-x} \mathrm{Si}_{x} \mathrm{O}_{12}(0 \leq x \leq 3)$ has a minimum $\mathrm{Na}^{+}$-ion resistivity of $\leq 5$ $\Omega \cdot \mathrm{cm}$ at $300{ }^{\circ} \mathrm{C}$, which is similar as that of the conventional sodium-ion conductor $\beta^{\prime \prime}$-alumina $[1,2]$. The crystal structure is rhombohedral $(R \overline{3} c)$ and tends, depending on composition, towards a monoclinic distortion. There are several studies on synthesis, substitution and conductivity in literature (e.g. [3-6]); however, very few reports deal with the mechanical properties $[7,8]$.

In addition to high ionic conductivity, a solid electrolyte should exhibit necessary mechanical reliability. Therefore, it is necessary to gain more knowledge on mechanical performance to warrant safety and reliability. It has been reported that Na-S batteries with $\beta / \beta^{\prime \prime}$-alumina revealed failure due to Na filaments that have propagated through the solid electrolyte [9-11]. In fact, the fracture toughness is a crucial parameter for crack growth and hence potentially for shortcircuiting in solid-state batteries [12,13].

The indentation is a frequently used method to derive fracture toughness values, which requires only a small materials’ volume and simple specimens’ preparation. Cracks are induced by a sharp stylus, mostly Vickers or Berkovich type, and the length of the resultant cracks that are induced above a critical load is measured. For the fracture toughness calculation, due to the relationship to elastic and plastic volume, knowledge of elastic modulus and hardness is a prerequisite [14-15]. 
Furthermore, the elastic modulus is also a very important parameter when designing a solid-state battery [16-22]. The solid electrolytes should deform elastically and accommodate internal stresses and should be able to assure a good electrode/electrolyte interface [23].

Thus, the purpose of this study is the determination of the mechanical properties of NASICON solid electrolyte with double substitution of $\mathrm{Zr}^{4+}$ with $\mathrm{Al}^{3+}$ and $\mathrm{Y}^{3+}$ [24]. Elastic modulus, hardness and fracture toughness are determined via indentation testing as function of the applied load, and potential correlations with substitution level and microstructural features are discussed.

\section{Experimental}

The NASICON solid solutions $\mathrm{Na}_{1+2 x} \mathrm{Al}_{x} \mathrm{Y}_{x} \mathrm{Zr}_{2-2 x}\left(\mathrm{PO}_{4}\right)_{3}(\mathrm{NAYZP} x, 0 \leq x \leq 0.25)$ and $\mathrm{Na}_{3+2 x} \mathrm{Al}_{x} \mathrm{Y}_{x} \mathrm{Zr}_{2-2 x}\left(\mathrm{SiO}_{4}\right)_{2}\left(\mathrm{PO}_{4}\right)$ (NAYZSiP $x, 0 \leq x \leq 0.3$ ) were prepared using the Pechini method [5]. The obtained gels were fired at $600{ }^{\circ} \mathrm{C}$ for $3 \mathrm{~h}$ and amorphous precursors were formed and calcined at $800{ }^{\circ} \mathrm{C}$ for $12 \mathrm{~h}$. The calcined powders were milled and pressed into pellets. The NAYZP $x$ pellets were sintered at $1200{ }^{\circ} \mathrm{C}$ for $10 \mathrm{~h}$ in air, whereas the NAZYSiP $x$ samples were exposed to a two-step sintering process, first at $1200{ }^{\circ} \mathrm{C}$ for $0.5 \mathrm{~h}$ and then at $1150{ }^{\circ} \mathrm{C}$ for $5 \mathrm{~h}$ in air. More details of synthesis can be found in [24]. The relative density of the specimens was within the range 85 to $93 \%$.

Phase purity of the sintered specimens was controlled by X-ray diffraction. Rietveld refinement was performed to calculate the lattice parameters [24]. The microstructure was characterized using cross-sections by field emission scanning electron microscopy (FE-SEM; Zeiss Merlin). The grain size distribution was determined using the software AnalySIS Pro based on the circular intercept segment mode. Electrical conductivity was measured using an impedance spectroscopy 
system (Biologic, VMP300) from $-30{ }^{\circ} \mathrm{C}$ to $100{ }^{\circ} \mathrm{C}$ in the frequency range $4 \mathrm{MHz}$ to $300 \mathrm{~Hz}$ using sputtered gold as blocking electrodes.

The indentation method was used to evaluate hardness $(H)$, elastic modulus $(E)$ and fracture toughness $\left(K_{I C}\right)$. Cross-sections of pellets were embedded in epoxy resin and finely polished via alumina suspension. A matrix of $5 \times 5$ indentation imprints was performed for each load. $H$ and $E$ values based on Oliver-Pharr procedure [25] were obtained as function of the applied loads, i.e. at $50 \mathrm{mN}, 100 \mathrm{mN}$ and $1000 \mathrm{mN}$, using a Fischer HC100 machine with a Vickers diamond tip, see also [26,27]. Poisson's ratio for all compositions was assumed to be 0.27 [7].

The fracture toughness, $K_{I C}$, was derived from the cracks induced from the corners of indentations after loading to $1 \mathrm{~N}, 2.94 \mathrm{~N}, 4.9 \mathrm{~N}$ and $9.81 \mathrm{~N}$. The dependence of cracks lengths and hence fracture toughness on the load was checked. Due to the load limitations, the Fischer HC100 machine was used only for 1 N, while for higher loads a Micromet, Buehler Ltd., was employed. $K_{I C}$ was derived on the basis of a Palmqvist crack system, since it was observed that crack lengths $(l)$ and half-diagonals $(a)$ were in the range $0.25 \leq l / a \leq 2.5$. The used Niihara equation reads [14]:

$$
K_{I C}=0.035\left(\frac{H \cdot a^{0.5}}{\phi}\right)\left(\frac{E \phi}{H}\right)^{0.4}\left(\frac{a}{l}\right)^{0.5}
$$

where $E$ is the elastic modulus, $H$ the hardness and $\phi$ a constraint factor (typically 3 is used). Elastic modulus and hardness obtained at $50 \mathrm{mN}$ were used to calculate $K_{I C}$, since these load load values are assumed to be representative for the intrinsic material's properties. Microstructure and 
indentation imprints were visualized by SEM, permitting also measurement of the crack lengths, which was carried out immediately after the impression.

\section{Results and discussion}

From the X-ray diffraction patterns it was identified that the NAYZPx are in rhombohedral phase with space group $R \overline{3} c$, and some minor secondary phase content $\left(\mathrm{YPO}_{4}, \mathrm{AlPO}_{4}, \mathrm{ZrO}_{2}\right)$ for $x$ being in the range of 0 to 0.15 and $x$ equal to 0.25 . In case of the sample with $x=0.20$ the amount of $\mathrm{YPO}_{4}$ is unusual high, about 10 wt.\%, and in case of $x>0.25$ a continuous increase in $\mathrm{YPO}_{4}$ and $\mathrm{Na}_{3} \mathrm{Y}_{2}\left(\mathrm{PO}_{4}\right)_{3}$ with increasing $x$ indicates that the solid solution is at its limit [24]. For NAYZSiP $x$ a monoclinic structure was found in the range $0 \leq x \leq 0.1$ and a transition to a rhombohedral phase for $0.2<x<0.3$, with a small amount of monoclinic $\mathrm{ZrO}_{2}$ detected in all compositions. Table 1 summarizes space group, lattice parameters and ionic conductivity $(\sigma)$ at room temperature for all samples, where $\mathrm{a}_{\text {hex }}$ and $\mathrm{chex}_{\text {ex }}$ are the hexagonal lattice constants and $\mathrm{a}_{\mathrm{r}}$ is the rhombohedral lattice constant.

Table 1- Composition, space group, lattice parameters and room temperature ionic conductivity for the $\mathrm{Na}_{1+2 x} \mathrm{Al}_{x} \mathrm{Y}_{x} \mathrm{Zr}_{2-2 x}\left(\mathrm{SiO}_{4}\right)_{y}\left(\mathrm{PO}_{4}\right)_{3}$ system.

\begin{tabular}{|c|c|c|c|c|c|}
\hline Composition & $\begin{array}{l}\text { Space } \\
\text { group }\end{array}$ & $\begin{array}{l}a_{\text {hex }} \\
(\AA)\end{array}$ & $\begin{array}{l}\text { Chex } \\
(\AA)\end{array}$ & $\begin{array}{l}\mathrm{a}_{\mathbf{r}} \\
(\AA)\end{array}$ & $\begin{array}{c}\sigma \\
\left(\mathrm{S} \mathbf{~ c m}^{-1}\right)\end{array}$ \\
\hline $\mathrm{NaZr}_{2}\left(\mathrm{PO}_{4}\right)_{3}$ & $\mathrm{R} \overline{3} \mathrm{c}$ & 8.805 & 22.776 & 9.137 & $3.1 \cdot 10^{-7}$ \\
\hline $\mathrm{Na}_{1.1} \mathrm{Al}_{0.05} \mathrm{Y}_{0.05} \mathrm{Zr}_{1.9}\left(\mathrm{PO}_{4}\right)_{3}$ & $\mathrm{R} \overline{3} \mathrm{c}$ & 8.812 & 22.779 & 9.140 & $1.1 \cdot 10^{-7}$ \\
\hline $\mathrm{Na}_{1.2} \mathrm{Al}_{0.1} \mathrm{Y}_{0.1} \mathrm{Zr}_{1.8}\left(\mathrm{PO}_{4}\right)_{3}$ & $\mathrm{R} \overline{3} \mathrm{c}$ & 8.816 & 22.789 & 9.144 & $5.0 \cdot 10^{-6}$ \\
\hline $\mathrm{Na}_{1.3} \mathrm{Al}_{0.15} \mathrm{Y}_{0.15} \mathrm{Zr}_{1.7}\left(\mathrm{PO}_{4}\right)_{3}$ & $\mathrm{R} \overline{3} \mathrm{c}$ & 8.824 & 22.805 & 9.151 & $6.0 \cdot 10^{-6}$ \\
\hline $\mathrm{Na}_{1.4} \mathrm{Al}_{0.2} \mathrm{Y}_{0.2} \mathrm{Zr}_{1.6}\left(\mathrm{PO}_{4}\right)_{3}$ & $\mathrm{R} \overline{3} \mathrm{c}$ & 8.830 & 22.820 & 9.157 & $6.2 \cdot 10^{-6}$ \\
\hline $\mathrm{Na}_{1.5} \mathrm{Al}_{0.25} \mathrm{Y}_{0.25} \mathrm{Zr}_{1.5}\left(\mathrm{PO}_{4)_{3}}\right.$ & $\mathrm{R} \overline{3} \mathrm{c}$ & 8.849 & 22.825 & 9.165 & $1.2 \cdot 10^{-6}$ \\
\hline $\mathrm{Na}_{3} \mathrm{Zr}_{2}\left(\mathrm{SiO}_{4}\right)_{2}\left(\mathrm{PO}_{4}\right)_{3}$ & $C 2 / c$ & $9.032 *$ & $23.042 *$ & 9.284 & $1.7 \cdot 10^{-3}$ \\
\hline $\mathrm{Na}_{3.1} \mathrm{Al}_{0.05} \mathrm{Y}_{0.05} \mathrm{Zr}_{1.9}\left(\mathrm{SiO}_{4}\right)_{2}\left(\mathrm{PO}_{4}\right)$ & $C 2 / c$ & $9.047 *$ & $23.021 *$ & 9.283 & $1.6 \cdot 10^{-3}$ \\
\hline $\mathrm{Na}_{3.2} \mathrm{Al}_{0.1} \mathrm{Y}_{0.1} \mathrm{Zr}_{1.8}\left(\mathrm{SiO}_{4}\right)_{2}\left(\mathrm{PO}_{4}\right)$ & $C 2 / c$ & $9.052 *$ & $22.948 *$ & 9.264 & $1.3 \cdot 10^{-3}$ \\
\hline $\mathrm{Na}_{3.4} \mathrm{Al}_{0.2} \mathrm{Y}_{0.2} \mathrm{Zr}_{1.6}\left(\mathrm{SiO}_{4}\right)_{2}\left(\mathrm{PO}_{4}\right)$ & $\mathrm{R} \overline{\overline{3}} \mathrm{c}$ & 9.096 & 22.741 & 9.222 & $1.4 \cdot 10^{-3}$ \\
\hline $\mathrm{Na}_{3.6} \mathrm{Al}_{0.3} \mathrm{Y}_{0.3} \mathrm{Zr}_{1.4}\left(\mathrm{SiO}_{4}\right)_{2}\left(\mathrm{PO}_{4}\right)$ & $\mathrm{R} \overline{3} \mathrm{c}$ & 9.110 & 22.671 & 9.207 & $4.6 \cdot 10^{-4}$ \\
\hline
\end{tabular}

*: transformed from the monoclinic system, values are only given for the sake of comparison. 
Figure 1 presents as examples the microstructures of NAYZP $x$ with $x=0.10,0.20$ and 0.25 and NAYSiZP $x$ with $x=0,0.05$ and 0.1 . The microstructures are rather homogeneous with small grain sizes, consistent and as expected for such powders obtained via the Pechini method.
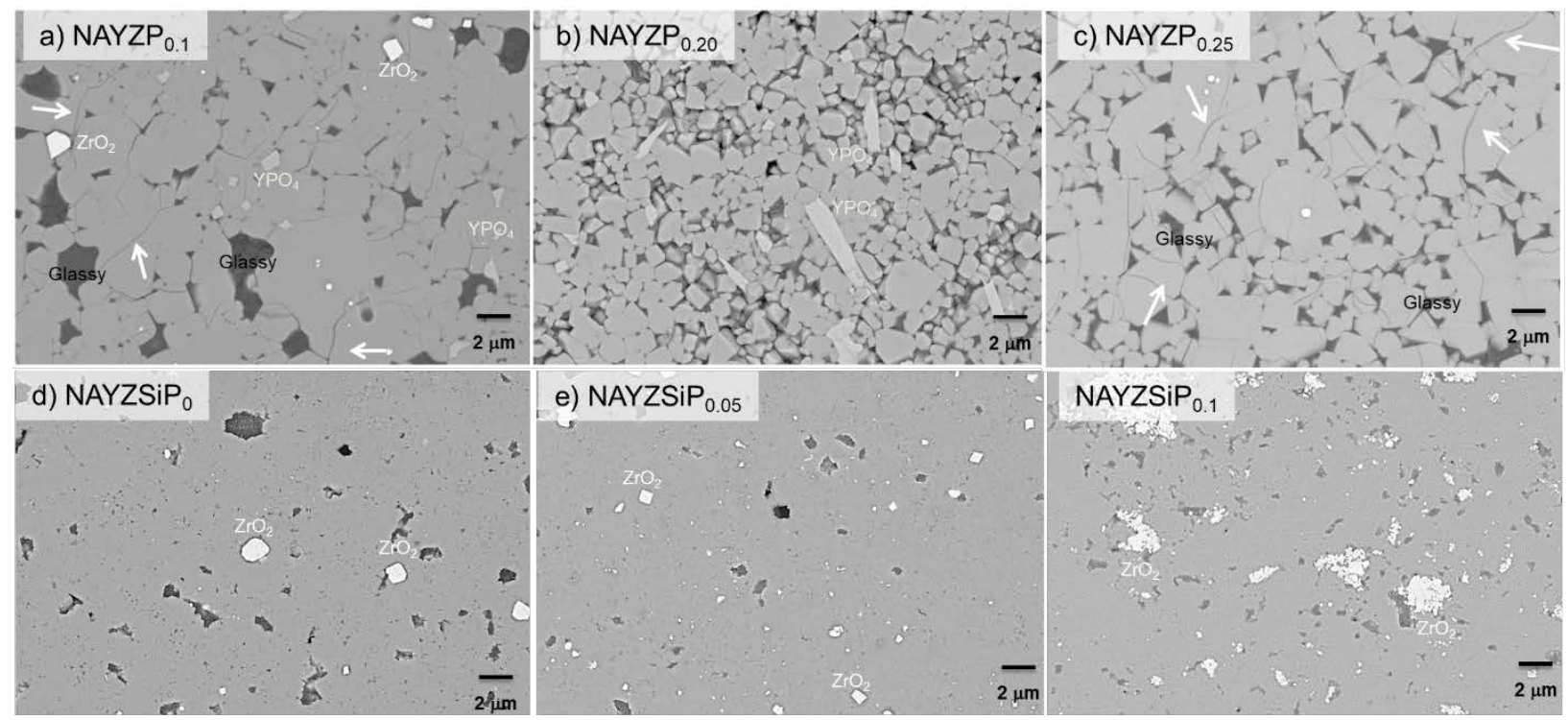

Figure 1- SEM images of polished cross-section of different NAYZPX and NAYZSiPx. Granular micro-cracks appear for non Si-substituted compositions NAYZPx as indicated by arrows. White $\mathrm{ZrO}_{2}$ and grey $\mathrm{YPO}_{4}$ secondary phases are also visible. The dark region between the grains is glassy phase $[24,28,29]$.

For the NAYZPx system, compositions with $x=0$ and $x=0.05$ did not fully densify at the sintering temperature and relative densities of only $52 \%$ and $75 \%$ were achieved. For $0.1 \geq x \geq 0.25$, the relative density of the samples varied between $87 \%$ and $91 \%$. However, overall microstructures were very similar. For NAYZPx with $x=0.1$ and 0.25 , micro-cracks were observed and $\mathrm{YPO}_{4}$ and $\mathrm{ZrO}_{2}$ as secondary phase, highlighted in Figure 1. 
Comparing the NAYZSiP $x$ specimens, relative densities varied from 85-93\% with rather similar microstructures for all compositions. In addition, the amount of $\mathrm{ZrO}_{2}$ secondary phase increased when $x$ was increased, as can be seen in Figure 1 .

\section{Elastic modulus and hardness - NAYZPx}

Figure 2 presents elastic modulus and hardness as a function of the applied load for the NAYZP $x$ system. Overall, $E$ and $H$ decrease with increasing the load. The decrease with load (depth) can be associated with a larger contribution of grain boundaries and porosity. At a low load of $50 \mathrm{mN}$ the penetration depths are around $600 \mathrm{~nm}$, so the properties for low loads are assumed to be representative of the materials intrinsic properties.
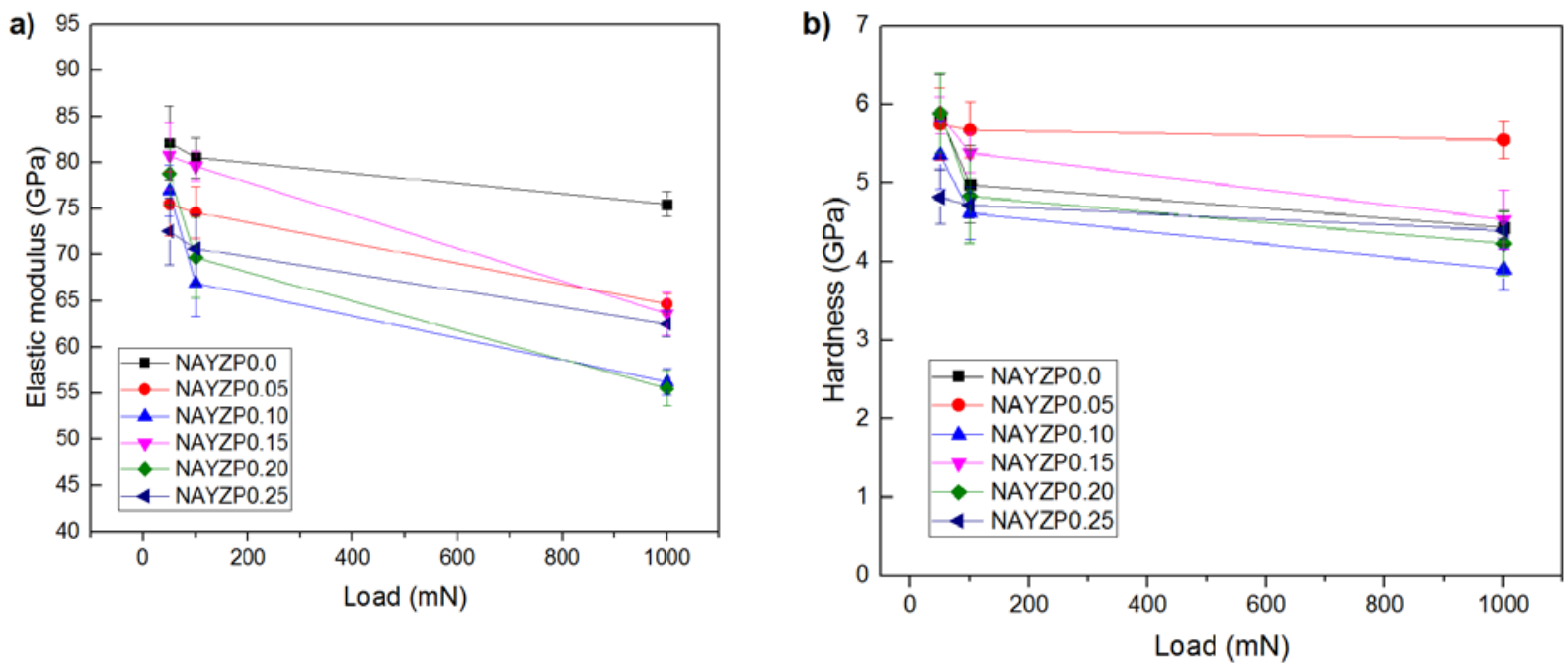

Figure 2- Elastic modulus and hardness as function of load for NAYZPX in (a) and (b).

Considering low load values, for the NAYZP $x$ series, the unsubstituted material $(x=0)$ possesses the highest elastic modulus of $82 \pm 4 \mathrm{GPa}$ and with increasing substitutional level values decrease 
to $73 \pm 4 \mathrm{GPa}$. Hardness values range from $5.8 \pm 0.5 \mathrm{GPa}$ for the unsubstituted to $4.8 \pm 0.3 \mathrm{GPa}$ for the material with maximum amount of substitution.

The values at low load are used to assess the compositional impact, see Figure 3. The unsubstituted material shows the highest values of mechanical parameters, followed by a reduction with increasing the $\mathrm{Al} / \mathrm{Y}$ content to 0.05 and 0.1 , and then a rise of the mechanical properties at 0.2 with again a diminution of $E$ and $H$ with increasing the substitution level to the maximum of 0.25 . In case of $x>0.25$ the continuous increase in $\mathrm{YPO}_{4}$ and $\mathrm{Na}_{3} \mathrm{Y}_{2}\left(\mathrm{PO}_{4}\right)_{3}$ with increasing $x$ that indicated that the solid solution was at its limit [24], might have led to reduced values.
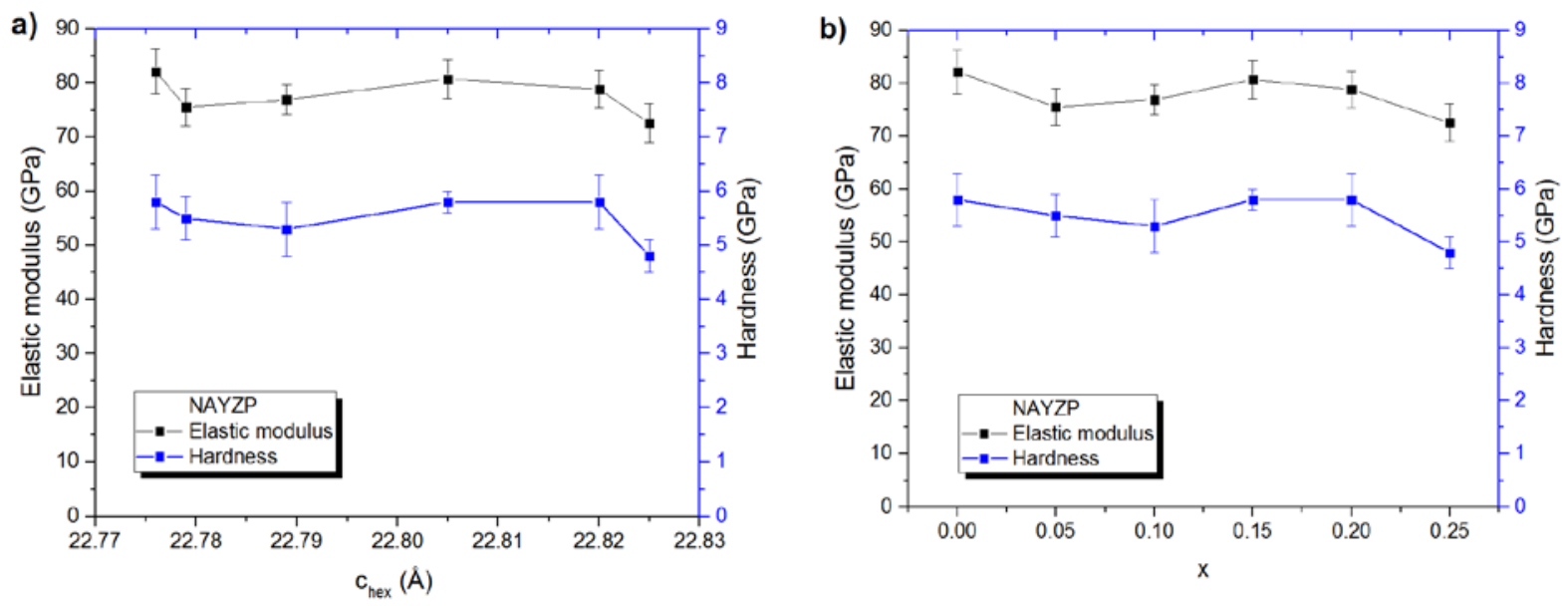

Figure 3- Elastic modulus and hardness of NAYZPx as function of a) hexagonal lattice parameter and b) composition $x$.

The elastic modulus is related to lattice parameters and atomic bonding. It can be expected that the larger the lattice parameter for the same crystal structure, the weaker the atomic bonding and therefore the lower the elastic modulus. In order to verify this relationship, $E$ and $H$ were plotted 
as function of hexagonal lattice parameter $c$ (data Table 1). In fact, plotting the data as a function of the rhombohedral lattice constant, in order to consider also the hexagonal a-axis, would lead to an equivalent representation since hexagonal and rhombohedral lattice parameter are almost linear proportional, see Table 1.

The calculated elastic modulus of $\mathrm{NaZr}_{2}\left(\mathrm{PO}_{4}\right)_{3}$ with space group $R \overline{3} c$ is $120.9 \mathrm{GPa}$ [30], which is much higher than the value obtained experimentally for the NAYZP $x$ in this work. This difference might be attributed to fact that the measured values are for polycrystalline samples and depend on various additional factors such as local porosity and grain boundaries, in addition the theoretical value is normally calculated at $0 \mathrm{~K}$ and a decrease with increasing temperature can be expected.

\section{Elastic modulus and hardness - NAYZSiPx}

Figure 4 presents elastic modulus and hardness as a function of the applied load for the NAYZSiPx system. Again, $E$ and $H$ decrease with increasing the load. The mechanical properties reveal a stronger dependency on the load compared to the NAYZPx series, see Figure 2. For reasons leading to a decrease with increasing load see previous section, the properties for low loads are assumed to be representative of the materials intrinsic properties. 

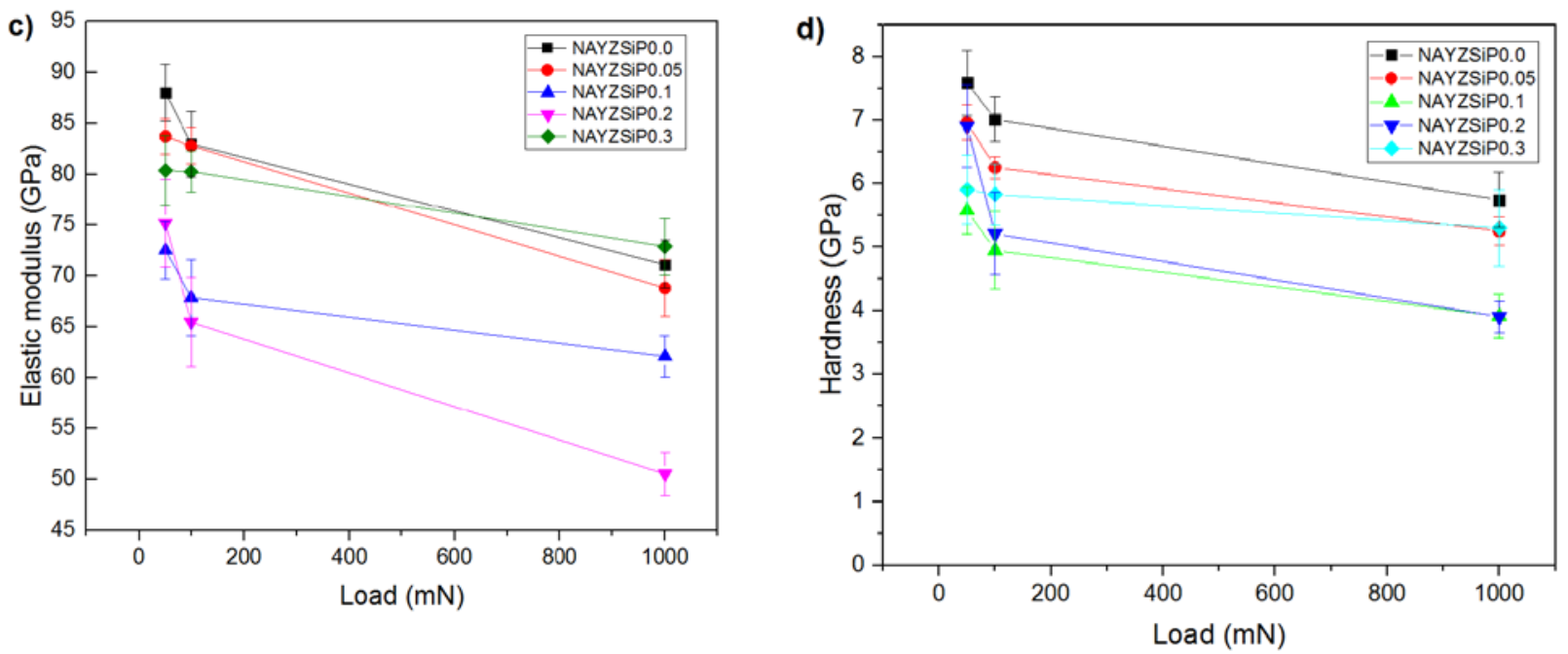

Figure 4- Elastic modulus and hardness as function of load for NAYZSiPx in (a) and (b).

For the NAYZSiP $x$, again, the unsubstituted material has the highest elastic modulus of $88 \pm 3$ GPa and the lowest is found for NAYZSiP0.1 with $73 \pm 3 \mathrm{GPa}$. Elastic modulus and hardness of NAYSiP $x$ are shown in Figure 5 as function of hexagonal lattice parameter and composition $x$. Overall, behavior is rather complex with maximum values for low $x$ (high Chex $_{\text {). Note, for }}$ NAYZSiP $x$ a monoclinic structure was found in the range $0 \leq x \leq 0.1$ and a transition to a rhombohedral phase for $0.2<x<0.3$, with a small amount of monoclinic $\mathrm{ZrO}_{2}$ was detected in all compositions, where especially the monoclinic structure might be responsible for the higher data at low $x$. 

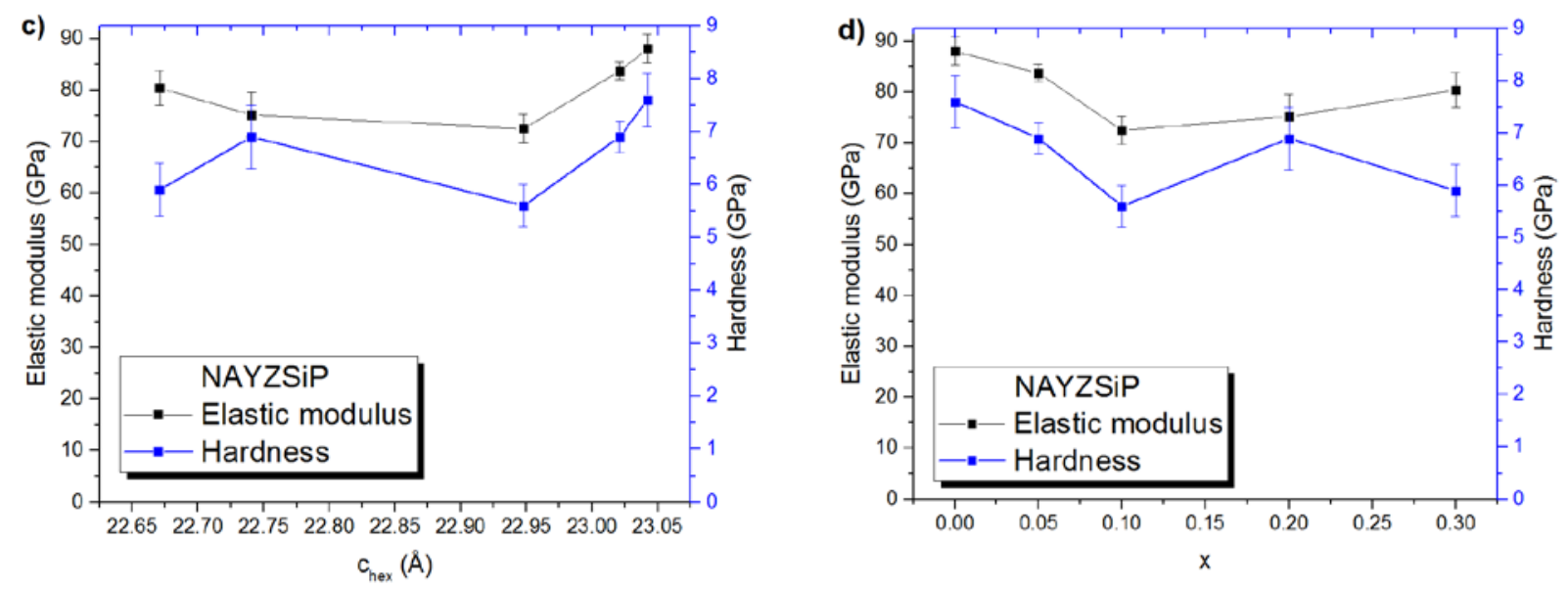

Figure 5- Elastic modulus and hardness of NAYSiPx as function of a) hexagonal lattice parameter and b) composition $x$.

\section{Fracture toughness - NAYZPx}

For NAYZP $x$ the ratio $l / a$ is in the range of 0.7 to 1.3 , fulfilling the requirement of $0.25 \leq l / a \leq$ 2.5 for Palmqvist crack system. Figure 6 presents the indentation marks on the surface of NAYZP0.05 and NAYZP0.10 for different loads. It can be clearly seen that the cracks do not propagate along a straight line, but have a tortuous path, showing typically a combined intergranular / transgranular fracture mode. This can be related to the week bonding between grains. Furthermore, due this complex non-linear crack path, it is very complicated to determine precisely the crack length. For the applied load of $1 \mathrm{~N}$, it was not possible to determine the crack length due the complex interaction of crack shape with microstructure; for the other loads the crack length was measured using the software AnalySIS Pro.

Crack lengths and fracture toughness values are compiled in Figure 7. The slight increase of $K_{I C}$ for some compositions at higher loads might be a result of start of fracture path changes from Palmqvist to median / radial. 
NAYZP0.05
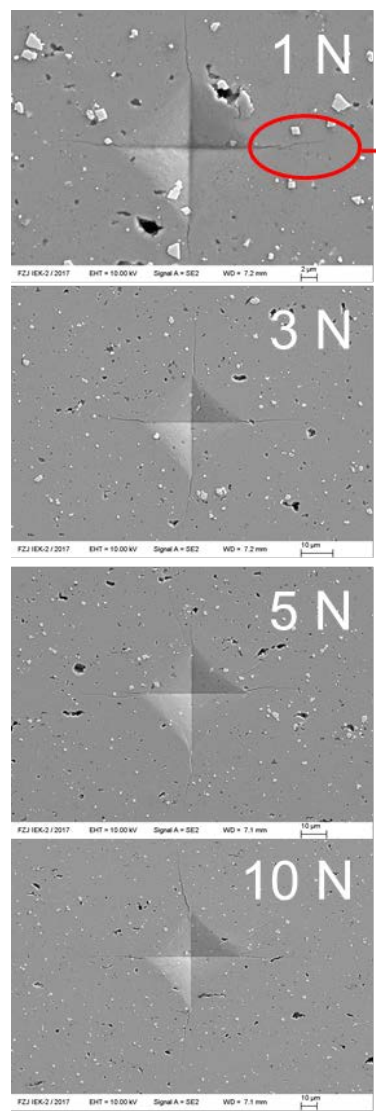
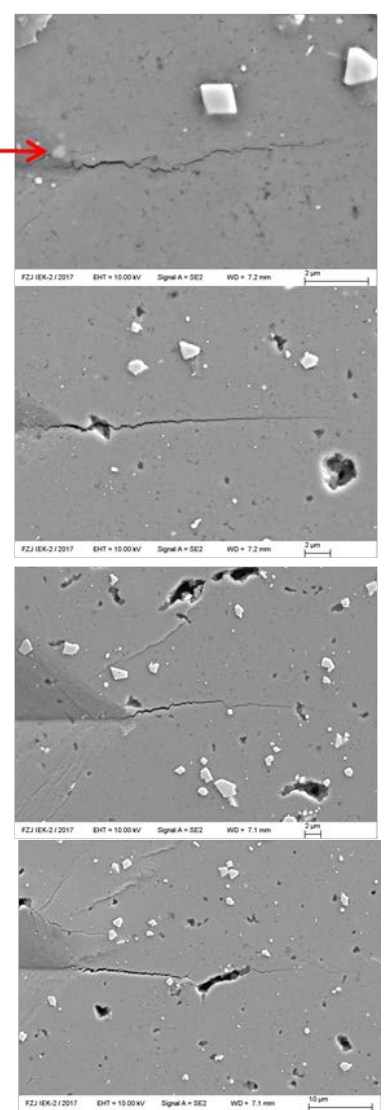

NAYZP0.10
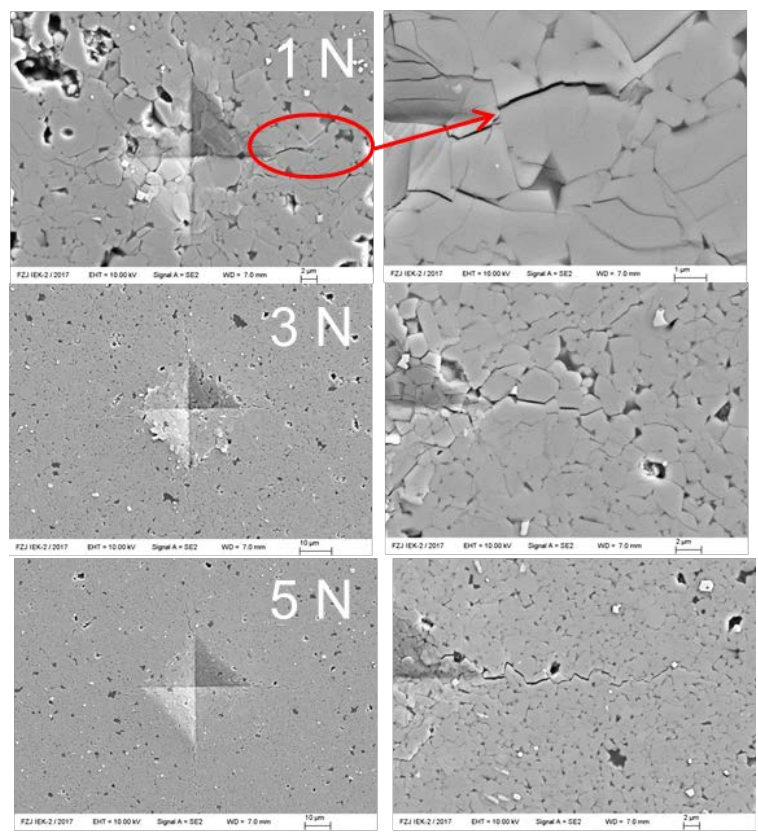

$10 \mathrm{~N}$
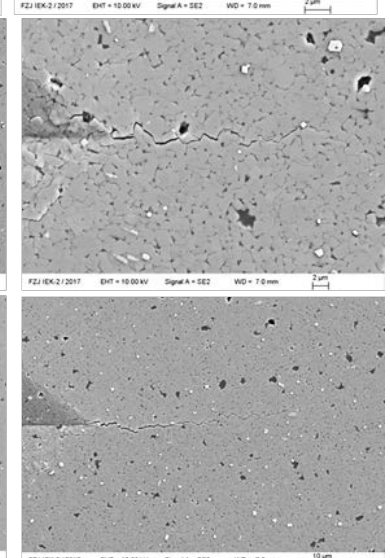

Figure 6- Indentation marks on NAYZP0.05 and NAYZP0.10 with 1 N, 3 N, 5 N and 10 N; fracture path is highlighted in red.
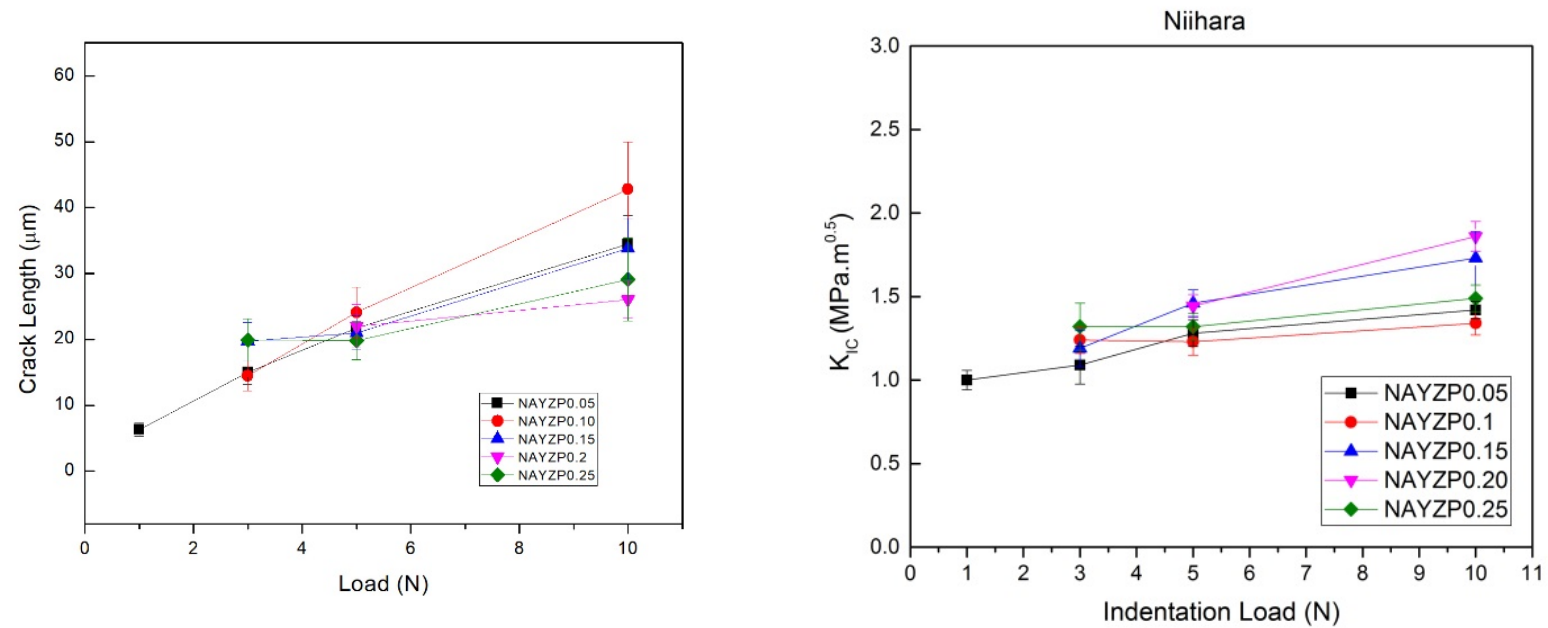

Figure 7- Crack length (a) and fracture toughness (b) of NAYZPx as function of load. 
For NAYZP0.0 no measurable cracks could be observed for any load due to the complex crack shape, the same happened for other compositions at loads of 1 and $3 \mathrm{~N}$. Therefore fracture toughness was not calculated in these cases. At $5 \mathrm{~N}$, values could be obtained and corresponding values are shown in Figure 8.

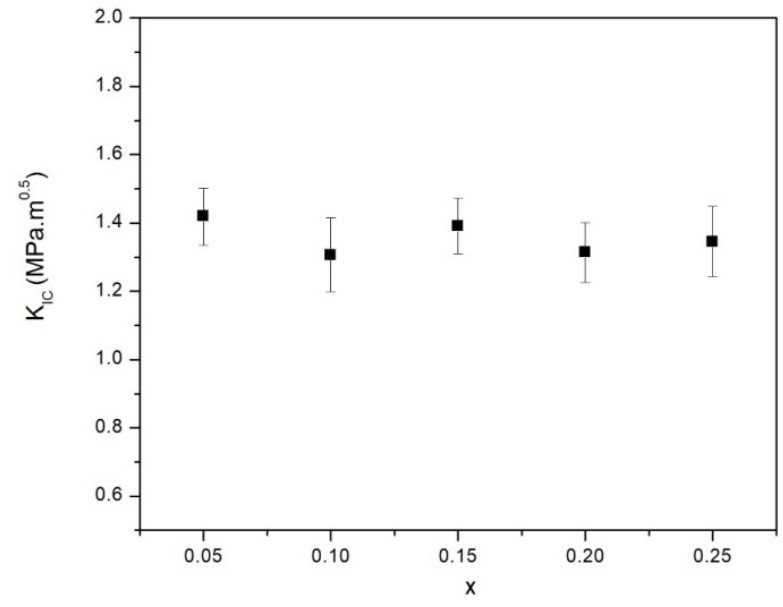

Figure 8- Fracture toughness of NAYZP $x$ for $0.05<x<0.3(\operatorname{load} 5 \mathrm{~N})$.

The values showed no significant variation with composition, being $1.3 \pm 0.1 \mathrm{MPa} \cdot \mathrm{m}^{0.5}$ for NAYZP0.1 and $1.4 \pm 0.1 \mathrm{MPa} \cdot \mathrm{m}^{0.5}$ for NAYZP0.05, overall with a similar dependence as for the elastic modulus. Hence, the composition has small influence on the fracture toughness.

\section{Fracture toughness - NAYZSiPx}

A similar investigation was performed on the series NAYZSiPx. Figure 9 shows typical indentation marks for NAYZSiP0.2 and NAYZP0.3. Values of $K_{\text {IC }}$ as function of load are shown in Figure 9. For the applied load of $1 \mathrm{~N}$, it was not possible to measure crack lengths, therefore 
images are not shown here. A slight increase of fracture toughness above $10 \mathrm{~N}$ might have been a result of initial changes from Palmqvist to median / radial crack type.

\section{NAYZSiP0.2}
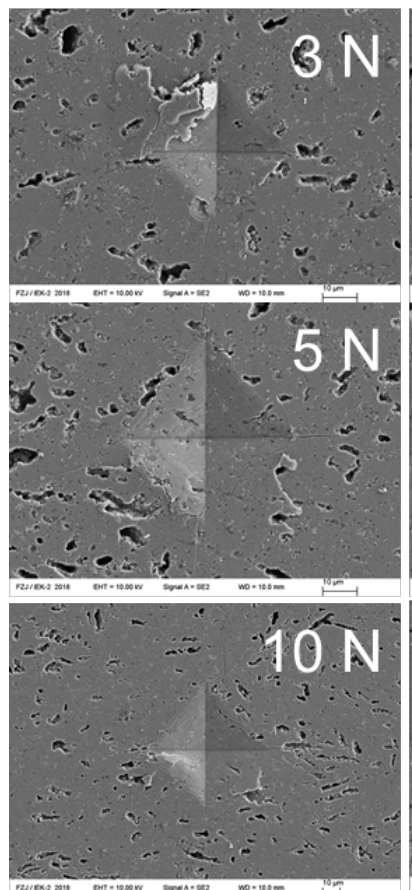
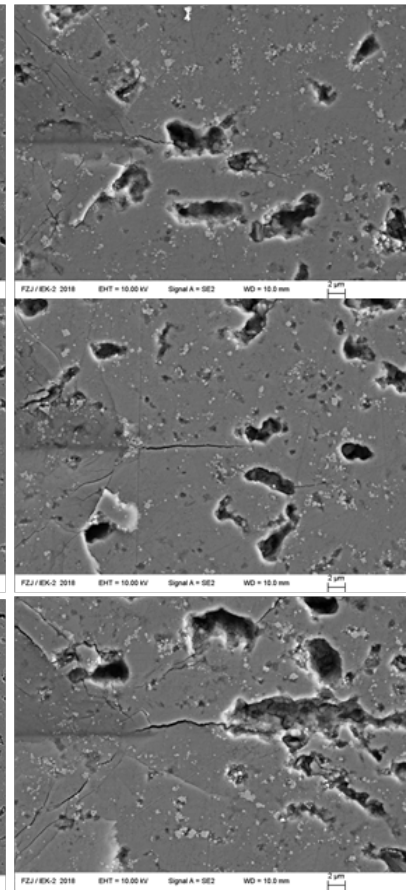

NAYZP0.3
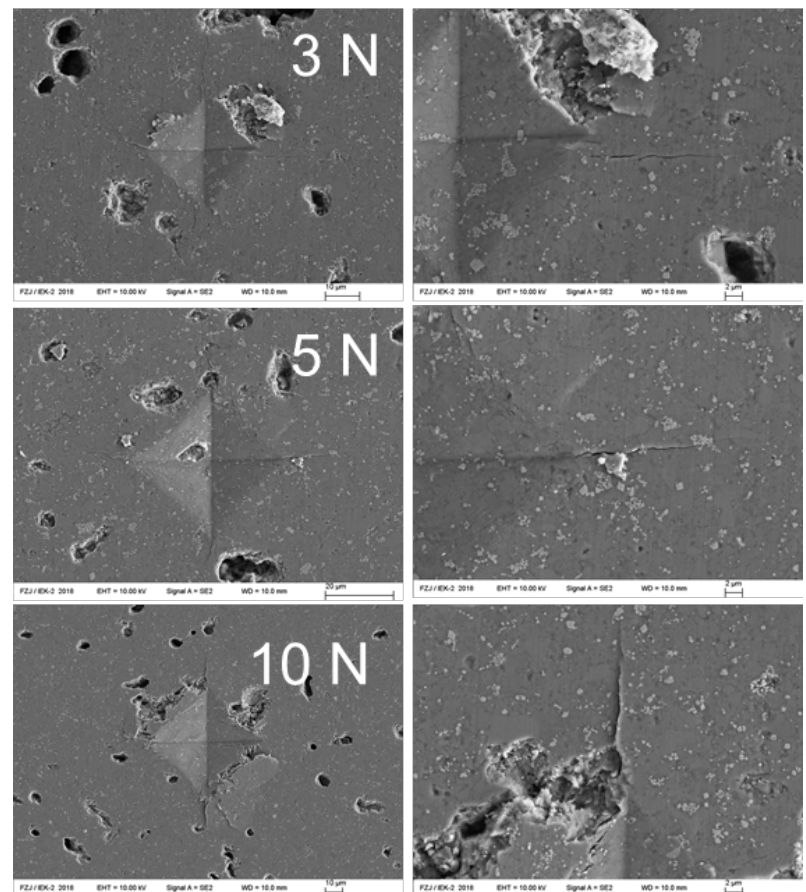

Figure 9- Indentation marks for NAYZSiP0.2 and NAYZP0.3 with 3 N, 5 N and 10 N.

The impressions at $5 \mathrm{~N}$ yielded well developed cracks, therefore the fracture toughness at $5 \mathrm{~N}$ was used to assess compositional effects, see Figure 10. The $K_{\text {IC }}$ values slightly increase up to $x=$ 0.1 and then decrease towards $x=0.3$, varying from $1.85 \pm 0.15 \mathrm{MPa} \cdot \mathrm{m}^{0.5}$ for NAYZSiP0.1 to $1.49 \pm 0.04 \mathrm{MPa} \cdot \mathrm{m}^{0.5}$ for NAYZSiP0.3. 

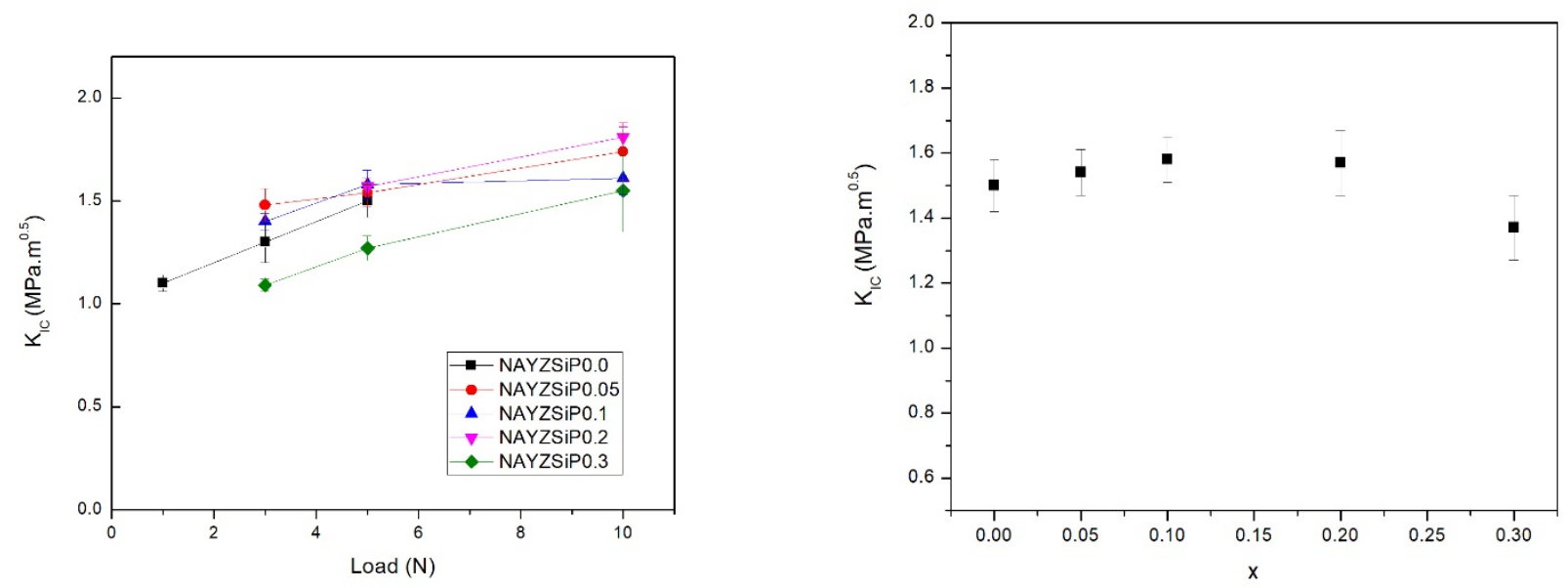

Figure 10- Fracture toughness of NAYZSiP $x$ with $0.0<x<0.3$ obtained at 1, 3, 5, and $10 \mathrm{~N}$ in (a) and at $5 \mathrm{~N}$ in (b) as a function of substitutional level.

\section{Conclusions}

Mechanical properties of NASICON-type materials with double substitution of Zr with $\mathrm{Al}$ and Y were assessed via depth-sensitive indentation. The dependency of elastic modulus, hardness and fracture toughness on applied load and composition was investigated.

Elastic modulus of NAYZPx showed a dependency on applied load, whereas hardness remained constant. Elastic moduli derived from low load data decreased from $82 \pm 4 \mathrm{GPa}$ for $\mathrm{NaZr}\left(\mathrm{PO}_{4}\right)_{3}$ (NAYZPx) to $73 \pm 4 \mathrm{GPa}$ for $\mathrm{Na}_{3.5} \mathrm{Al}_{0.25} \mathrm{Y}_{0.25} \mathrm{Zr}_{1.5}\left(\mathrm{PO}_{4}\right)_{3}$ and hardness from $5.8 \pm 0.5 \mathrm{GPa}$ and 4.8 $\pm 0.3 \mathrm{GPa}$. Fracture toughness evaluated at $5 \mathrm{~N}$ ranged from $1.3 \pm 0.1 \mathrm{MPa} \cdot \mathrm{m}^{0.5}$ for NAYZP0.1 to $1.4 \pm 0.1 \mathrm{MPa} \cdot \mathrm{m}^{0.5}$ for NAYZP0.05.

For NAYZSiP $x, \mathrm{Na}_{3} \mathrm{Zr}_{2}\left(\mathrm{SiO}_{4}\right)_{2}\left(\mathrm{PO}_{4}\right)$ possessed the highest elastic modulus (88 $\pm 3 \mathrm{GPa}$ ) and the lowest was obtained for $\mathrm{Na}_{3.2} \mathrm{Al}_{0.1} \mathrm{Y}_{0.1} \mathrm{Zr}_{2.8}\left(\mathrm{SiO}_{4}\right)_{2}\left(\mathrm{PO}_{4}\right)(73 \pm 3 \mathrm{GPa})$, both crystallizing in monoclinic structure. Rhombohedral NAYZSiP0.2 and NAYZSiP0.3 have rather similar values 
within the same range of uncertainty of $75 \pm 4 \mathrm{GPa}$ and $80 \pm 3 \mathrm{GPa}$, respectively. Hardness varies from $7.6 \pm 0.5 \mathrm{GPa}$ for $\mathrm{Na}_{3} \mathrm{Zr}_{2}\left(\mathrm{SiO}_{4}\right)_{2}\left(\mathrm{PO}_{4}\right)$ to $5.6 \pm 0.4 \mathrm{GPa}$ for $\mathrm{Na}_{3.2} \mathrm{Al}_{0.1} \mathrm{Y}_{0.1} \mathrm{Zr}_{2.8}\left(\mathrm{SiO}_{4}\right)_{2}\left(\mathrm{PO}_{4}\right)$. Focusing on the influence of composition on fracture toughness, the values at $5 \mathrm{~N}$ tended to remain rather constant up to NAYZSiP0.2 and slightly decreased to $1.4 \pm 0.1 \mathrm{MPa} \cdot \mathrm{m}^{0.5}$ for NAYZSiP0.3.

\section{Acknowledgements}

This work was supported by the National Council for Scientific and Technological Development under grant number: 232838/2014-3 (CNPq)-Brazil. The authors would also like to especially thank to Dr. E. Wessel, M. Ziegner for their cooperation with structural characterization, as well as to Prof. Dr. M. Krüger, Prof. Dr. L. Singheiser and Prof. Dr. O. Guillon for support.

\section{References}

1. J.B. Goodenough, H.Y.P. Hong, J.A. Kafalas, Fast $\mathrm{Na}^{+}$-ion transport in skeleton structures, Mater. Res. Bull. 11 (1976) 203-220.

2. H.Y.P. Hong, Crystal structures and crystal chemistry in the system $\mathrm{Na}_{1+\mathrm{x}} \mathrm{Zr}_{2} \mathrm{Si}_{\mathrm{x}} \mathrm{P}_{3-\mathrm{x}} \mathrm{O}_{12}$, Mater. Res. Bull. 11 (1976) 173-182.

3. M. Guin, F. Tietz, O. Guillon, New promising NASICON material as solid electrolyte for sodium-ion batteries: Correlation between composition, crystal structure and ionic conductivity of $\mathrm{Na}_{3+\mathrm{x}} \mathrm{Sc}_{2} \mathrm{Si}_{\mathrm{x}} \mathrm{P}_{3-\mathrm{x}} \mathrm{O}_{12}$, Solid State Ionics 293 (2016) 18-26.

4. O. Bohnke, S. Ronchetti, D. Mazza, Conductivity measurements on NASICON and NASICON-modified materials, Solid State Ionics 122 (1999) 127-136.

5. S. Naqash, Q. Ma, F. Tietz, O. Guillon, $\mathrm{Na}_{3} \mathrm{Zr}_{2}\left(\mathrm{SiO}_{4}\right)_{2}\left(\mathrm{PO}_{4}\right)$ prepared by a solutionassisted solid state reaction, Solid State Ionics 302 (2017) 83-91. 
6. T. Takahashi, K. Kuwabara, M. Shibata, Solid-state ionics - conductivities of $\mathrm{Na}^{+}$ion conductors based on NASICON. Solid State Ionics 1 (1980) 163-175.

7. Z. Deng, Z. Wang, I.-H. Chu, J. Luo, S.P. Ong, Elastic properties of alkali superionic conductor electrolytes from first principles calculations, J. Electrochem. Soc. 163 (2016) A67A74.

8. A.V. Virkar, G.J. Tennenhouse, R.S. Gordon, Hot-pressing of $\mathrm{Li}_{2} \mathrm{O}$-stabilized $\beta^{\prime \prime}-$ Alumina. J. Am. Ceram. Soc. 57 (1974) 508-508.

9. X. Lu, G. Xia, J.P. Lemmon, Z. Yang, Advanced materials for sodium-beta alumina batteries: Status, challenges and perspectives, J. Power Sources 195 (2010) 2431-2442.

10. M. Ohshima, A. Kobayashi, A. Yoshida, H. Tsuji, Verification of the fracture mechanism of $\beta^{\prime \prime}$-aluminas caused by large current density, Electrical Engineering in Japan 111 (1991) 11-23.

11. L. Viswanathan, A.V. Virkar, Crack-propagation rates in $\beta^{\prime \prime}$-alumina, J. Am. Ceram. Soc. 66 (1983) 159-162.

12. R. Raj, J. Wolfenstine, Current limit diagrams for dendrite formation in solid-state electrolytes for Li-ion batteries, J. Power Sources 343 (2017) 119-126.

13. E. J. Cheng, A. Sharafi, J. Sakamoto, Intergranular Li metal propagation through polycrystalline $\mathrm{Li}_{6.25} \mathrm{Al}_{0.25} \mathrm{La}_{3} \mathrm{Zr}_{2} \mathrm{O}_{12}$ ceramic electrolyte, Electrochim. Acta 223 (2017) 85-91.

14. K. Niihara, A fracture mechanics analysis of indentation-induced Palmqvist crack in ceramics, J. Mater. Sci. Lett. 2 (1983) 221-223.

15. G.R. Anstis, P. Chantikul, B.R. Lawn, D.B. Marshall, A critical evaluation of indentation techniques for measuring fracture toughness: I, direct crack measurements, J. Am. Ceram. Soc. 64 (1981) 533-538.

16. A.G. Evans, E.A. Charles, Fracture toughness determinations by indentation, J. Am. Ceram. Soc. 59 (1976) 371-372. 
17. X. Hu, G. Yan, X. Cheng, J. Malzbender, W. Qiang, B. Huang, Electrochemical and mechanical stability of $\mathrm{Li}_{x} \mathrm{La}_{0.557} \mathrm{TiO}_{3-\delta}$ perovskite electrolyte at various voltages, J. Am. Ceram. Soc. 102 (2019) 1953-1960.

18. X. Hu, X. Cheng, S. Qin, G. Yan, J. Malzbender, W. Qiang, B. Huang, Mechanical and electrochemical properties of cubic and tetragonal $\mathrm{Li}_{x} \mathrm{La}_{0.557} \mathrm{TiO}_{3}$ perovskite oxide electrolytes, Ceram. Int. 44 (2018) 1902-1908.

19. G. Yan, J.F. Nonemacher, H. Zheng, M. Finsterbusch, J. Malzbender, M. Krüger, An investigation on strength distribution, subcritical crack growth and lifetime of the lithium-ion conductor $\mathrm{Li}_{7} \mathrm{La}_{3} \mathrm{Zr}_{2} \mathrm{O}_{12}$, J. Mater. Sci. 54 (2019) 5671-5681.

22. A.-N. Wang, J.F. Nonemacher, G. Yan, M. Finsterbusch, J. Malzbender, M. Krüger, Mechanical properties of the solid electrolyte Al-substituted $\mathrm{Li}_{7} \mathrm{La}_{3} \mathrm{Zr}_{2} \mathrm{O}_{12}$ (LLZO) by utilizing micro-pillar indentation splitting test, J. Euro. Ceram. Soc. 38 (2018) 3201-3209.

21. J.F. Nonemacher, C. Hüter, H. Zheng, J. Malzbender, M. Krüger, R. Spatschek, M. Finsterbusch, Microstructure and properties investigation of garnet structured $\mathrm{Li}_{7} \mathrm{La}_{3} \mathrm{Zr}_{2} \mathrm{O}_{12}$ as electrolyte for all-solid-state batteries, Solid State Ionics 321 (2018) 126-134.

22. G. Yan, S. Yu, J.F. Nonemacher, H. Tempel, H. Kungl, J. Malzbender, R.-A. Eichel, M. Krüger, Influence of sintering temperature on conductivity and mechanical behavior of the solid electrolyte LATP, Ceram. Int. 45 (2019) 14697-14703.

23. C. Monroe, J. Newman, The impact of elastic deformation on deposition kinetics at lithium/polymer interfaces, J. Electrochem. Soc. 152 (2005) A396-A404.

24. S. Naqash, F. Tietz, O. Guillon, Synthesis and characterization of equimolar al/ysubstituted NASICON solid solution $\mathrm{Na}_{1+2 x+y} \mathrm{Al}_{\mathrm{x}} \mathrm{Y}_{\mathrm{x}} \mathrm{Zr}_{2-2 \mathrm{x}} \mathrm{Si}_{\mathrm{y}} \mathrm{P}_{3-\mathrm{y}} \mathrm{O}_{12}$, Solid State Ionics 319 (2018) 13-21. 
25. W.C. Oliver, G.M. Pharr, An improved technique for determining hardness and elastic modulus using load and displacement sensing indentation experiments, J. Mater. Res. 7 (2011) 1564-1583.

26. J. Malzbender, Comment on hardness definitions, J. Euro. Ceram. Soc. 23 (2003) 13551359.

27. T. Wakui, J. Malzbender, R.W. Steinbrech, Surf. Coat. Technol. 200 (2006) 5419-5426.

28. S. Naqash, D. Sebold, F. Tietz, O. Guillon, Microstructure-conductivity relationship of $\mathrm{Na}_{3} \mathrm{Zr}_{2}\left(\mathrm{SiO}_{4}\right)_{2}\left(\mathrm{PO}_{4}\right)$ ceramics. J. Am. Ceram. Soc. 102 (2019) 1057-1070.

29. S. Naqash, F. Tietz, E. Yazhenskikh, M. Müller, O. Guillon, Impact of sodium excess on electrical conductivity of $\mathrm{Na}_{3} \mathrm{Zr}_{2} \mathrm{Si}_{2} \mathrm{PO}_{12}+x \mathrm{Na}_{2} \mathrm{O}$ ceramics, Solid State Ionics, 336 (2019) 57-66. 30. Z. Deng, Z. Wang, I.-H. Chu, J. Luo, S. Ong, Elastic properties of alkali superionic conductor electrolytes from first principles calculations, J. Electrochem. Soc. 163 (2016) A67A74. 